\title{
A Study on Factors Related to Disaster Management in Industries That Store Hazardous Materials
}

\author{
Chun-Hao Shao ${ }^{1}$, Pei-Chun Shao ${ }^{2 *}$, and Yu-Lun Chiou ${ }^{3}$ \\ ${ }^{1}$ Assistant Professor, Graduate School of Disaster Management, Central Police University, 33304 Taoyuan City, Taiwan (R.O.C) \\ ${ }^{2}$ Associate Professor, Department of Land Management and Development, Chang Jung University, 71101 Tainan City, Taiwan (R.O.C) \\ ${ }^{3}$ Officer of Disaster Reduction Planning Section, Taoyuan Fire Department, 33304 Taoyuan City, Taiwan (R.O.C)
}

\begin{abstract}
When disaster strikes, close relationships form between governments, businesses, and people. Since hazardous materials industries are dangerous, it is important to enhance their disaster prevention efforts. We examined the literature on hazardous materials management, business risk management, corporate social responsibility, and the promotion of disaster management in Taiwan. The study deals with these topics in five dimensions: "organization," "law," "consultation," "financial aid," and "education." These dimensions were used to create a questionnaire. An investigation of hazardous materials industries in Taiwan was conducted to explore the factors that could be used to promote their disaster management and improve their willingness. After the data were analyzed, the findings indicated the following: (1) Company capital affected motivation toward disaster management, especially as an organizational factor. (2) A company's employee population affected its selection of motivation factors. (3) When the government made disaster management policies, the differences between the hazardous materials industries and consultation and support persons were the main viewpoints related to the promotion of policies. (4) Two background variables, company capital and employee population, had an interaction on the motivation factor of organization. (5) Three motivation factors_- "organization," "consultation," and "financial aid" - could effectively predict an industry's intention toward business continuity management.
\end{abstract}

\section{Research background and purpose}

When an industry stops operating due to a disaster, not only is damage done to the industry's image and hardware, but also the socioeconomic system, employment, and community development are destroyed. Take B Company of Taoyuan City in Taiwan as an example. Nitrocellulose is its main product, and it is one of the top three nitrocellulose producers in the world. The company experienced an explosion accident in 2013, where half of the factory buildings were destroyed and business was stopped. Other supply chain manufacturers, which make oil-based color and ink, were influenced by the explosion and started obtaining nitrocellulose from other sources rather than B Company. In addition, C company, a printed circuit board maker in Taoyuan City, had a serious conflagration in 2018 that left five firefighters dead. It was caused by poor management of hazardous materials.

According to data from 2017 provided by the Fire Agency in Taiwan [1], there were 5,519 companies that stored hazardous materials. If they lack good management and risk control protocols, the related industries could be badly damaged and cause serious pollution in nearby communities and environments. Further, the recovery of a company is a time-consuming process that has an impact on the whole society. It is important to improve management practices and make a business continuity plan (BCP) on disaster mitigation for industries.

In order to prompt industries to implement disaster mitigation measures spontaneously, the factors that can encourage industries to manage the risk of conflagration and other natural hazards need to be understood by the government. In this study, we will explore these factors and their relationships with each other, and provide suggestions to the public sector (such as local governments or related agencies) on crafting disaster prevention policies. The research objectives are listed below.

1. We will explore the factors that can make industries that work with hazardous materials want to adopt disaster management measures.

2. We will elucidate the relationship among factors that influence industries' motivation to deal with disaster mitigation.

3. Based on the factors and their relationship, we will provide specific suggestions on how industries can employ business continuity management $(\mathrm{BCM})$ and make a BCP for disaster management.

\footnotetext{
*Corresponding author: peicshao1211@gmail.com
} 


\section{Literature review}

We reviewed related research on factors that may have an influence on BCM and disaster mitigation efforts by industries. At the end of this section, we provide a brief summary of the related factors.

\subsection{Factors with an influence on business continuity plans in the electronics industry}

Tsi [2] conducted a study on BCPs and grouped together three factors with a relationship with BCPs via factor analysis; they were "communication of risk to industry," "management of supply chain," and "sustainable operation." As for the sub-elements of these three factors, "internal organization," "management system," "exchange rate," and "human resources" are involved in "communication of risk to industry"; "management of supply chain" includes "disaster" and "stress of competition all over the world," which may affect the supply chain; and "strategy of operation," "education of employees," and "perspectives of supervisors" are attributed to "sustainable operation."

\subsection{Investigation into disaster mitigation and safety status for small and medium enterprises in the manufacturing industry}

$\mathrm{Li}$ and Cao [3] were entrusted by the Institute of Labor, Occupational Safety, and Health in Taiwan to conduct an investigation on disaster management and safety status for small and medium enterprises in the manufacturing industry. Based on the outcome of their questionnaire analysis, strategies were provided to improve environmental safety. The authors analyzed the related literature and grouped together five incentivizing factors, which were "organization," "law," "consultation," "financial aid," and "education." There were also 20 subfactors under these 5 factors. Based on the outcome of AHP, "education" was the most important, followed by "financial aid" and "consultation."

\subsection{Managing safety in small and medium enterprises}

Legg, Olsen, Laird, and Hasle [4] built a model of safe working environments in small and medium enterprises. They found that "law" was the most important factor in enhancing the safety of working environments. Besides, frequent checks of safety conditions, stakeholders' attention to safety, and sharing of related information between small and medium enterprises were also important indexes for industries when ensuring legal and safe working environments.

\subsection{Occupational health and safety management in small enterprises}

Champoux and Brun [5] conducted an investigation into companies whose employees numbered under 50 persons by telephone interview in Québec Prefecture, Canada.
They found that the limitations of human resources, capital, and technology in small companies led to poor management of disasters. When a government tries to improve the disaster management capability of an industry, a strategy designed for big enterprises cannot work with small companies. In other words, different industries should have customized disaster mitigation strategies.

\subsection{Motivational factors influencing small construction and auto repair enterprises to participate in occupational health and safety programs}

Kvorming, Hasle, and Christensen [6] conducted a case study on small construction and auto repair enterprises with the intention of analyzing motivations for participating in occupational health and safety programs. They found different ways for information distribution to affect motivation. Also, the content, cost, and arrangement of occupational health and safety programs could also affect the motivation to participate. Furthermore, the attitude of the government toward occupational health and safety programs, and the technology used in the programs, may have an influence on enterprises' motivation to participate.

\subsection{Summary of factors influencing industries' motivation to conduct disaster management}

Based on our review of the related studies, the factors that encourage industries involved with hazardous materials to prepare their BCM during normal times can be summarized as follows:

- Organization

- Law

- Financial aid

- Consultation

- Education

These factors were taken as a reference in this study. "Organization" means that disaster management should be under an organization that is in charge of BCM and makes the BCP. "Law" means that related regulations about disaster management for industries should be complete and enterprises should obey the laws. "Financial aid" means funds from the government that can help an industry deal with disaster management. "Consultation" means that assistance and advice from the government is essential when an industry tries to implement disaster management. Finally, "education" refers to drills and curricula in disaster management, $\mathrm{BCM}$, and $\mathrm{BCP}$ for industries, which should be provided by the government, NGOs, and NPOs during normal times.

\section{Research method and arrangement}

We conducted a questionnaire based on factors that may affect the disaster management motivation of industries with reference to past research. There were three parts to the questionnaire. The first part covered the subject's 
background and the attributes of their company. The second part covered the present disaster management status. The third part covered factors that could affect disaster management motivation when an industry is considering preparing its BCM. The factors were "organization," "law," "consultation," "financial aid," and "education." The third part also addressed the disaster management intentions of industries relating to different issues. More details on these three parts are given below, and the questionnaire's structure is shown in Fig. 1.

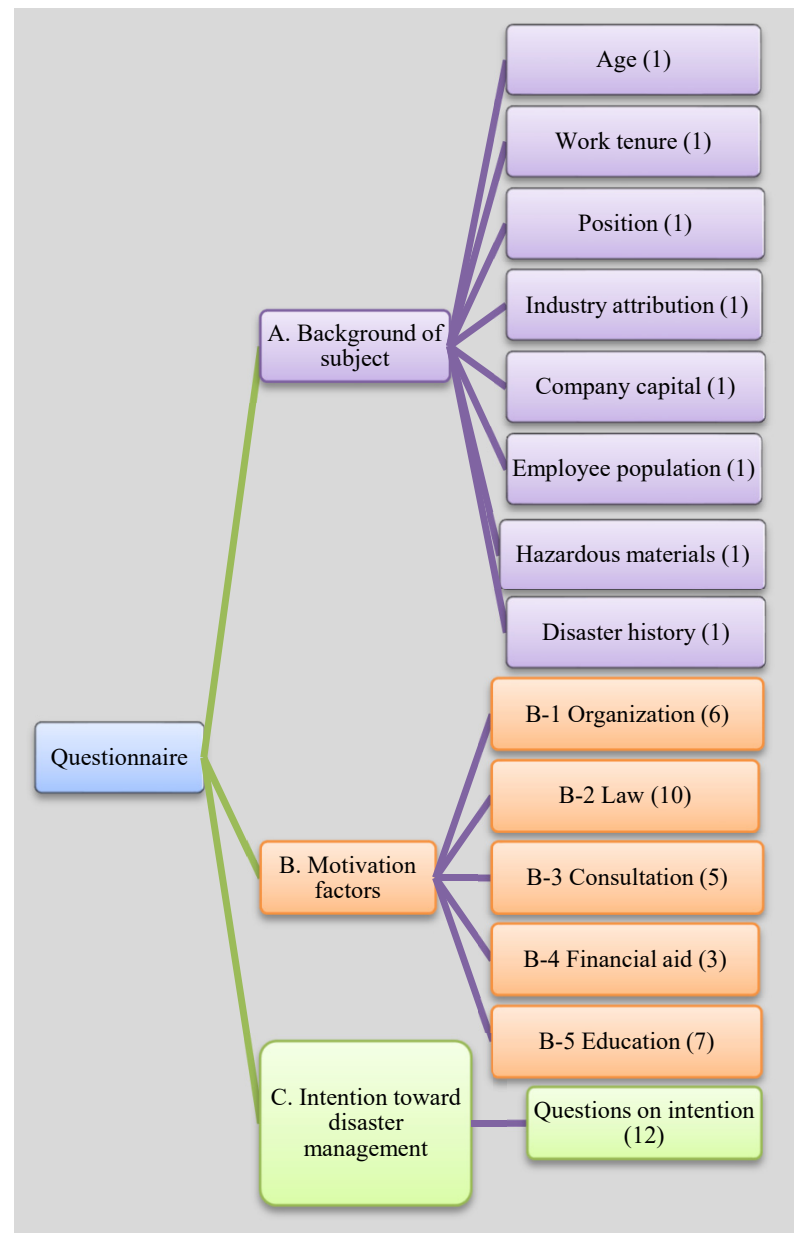

( ) indicates total no. of questions in the sub-factor

Fig. 1. Questionnaire structure

\subsection{Questionnaire content}

\subsubsection{Subject's background}

The first part of the questionnaire (Part A) focused on the subject's background, including "age," "work tenure," and "position." Also, there were questions about the industry, covering "industry attribution," "company capital," "employee population," "hazardous materials," and "disaster history." This part had a single-choice format.

The sub-classification of "industry attribution" was based on the "Occupational Safety and Health Act," which divides industries into three types: the first type includes the petrochemical and construction industries; the second includes the service industry, stock farming, medical industry, etc.; finally, industries that cannot be classified into the first or second types belong to the third type. Furthermore, the sub-classifications of "industry capital" and "employees" were based on the "Criteria of Small and Medium Enterprise" and the "Occupational Safety and Health Act." If an enterprise's capital was over 80,000,000 New Taiwan dollars (NT\$) (about $\$ 2,604,800$ ) and the employee population was over 200, it was regarded as a medium enterprise. If the capital and employee population were lower than that, it was a small enterprise, and if they were higher, it was considered a large enterprise.

\subsubsection{Motivation factors}

The second part (Part B) of the questionnaire dealt with motivation factors related to the industry's disaster management. Based on the literature review, we found five factors that can affect an industry's motivation to deal with disaster management. They are "organization (B-1)," "law (B-2)," "consultation (B-3)," "financial aid (B-4)," and "education (B-5)." There were 31 questions in total, which were distributed across the 5 factors in this part. The questions used Likert scales. The answers were coded from " 1 " to " 5 ," with " 1 " being the least important and "5" being the most important.

\subsubsection{Disaster management intentions}

The third part (Part C) of the questionnaire was based on the second part and asked the subjects whether they would have the will to implement disaster management if the motivation factors were fully provided. In this part, there were 12 questions in total. These questions also used a Likert scale, with answers ranging from " 1 " to " 5 "- the larger the number, the stronger the intention.

\subsubsection{Validity and reliability of the questionnaire}

We used a content validity index (CVI) to evaluate the questionnaire. Based on eight experts' evaluations, the CVI of the questionnaire was 0.86 , which was larger than 0.8 (the index value). When it came to reliability, we calculated the Cronbach's $\alpha$ value to check if the reliability could be proved. The $\alpha$ value was 0.92 , which was larger than 0.7 (the index value). Based on these evaluations, the validity and reliability of the questionnaire were supported.

\subsection{Sample and Questionnaire Survey}

For the study sample, we focused on Taiwanese companies that deal with hazardous materials. Based on data provided by the Fire Agency, there are 5,519 such companies in Taiwan. Under a 95\% confidence level, we chose 300 samples that were distributed across northern, central, and southern Taiwan. Based on the ratio of companies in these 3 areas, we sampled 105 companies in northern Taiwan, 83 in central Taiwan, and 112 in southern Taiwan.

After obtaining consent, we took the questionnaires 
to the sampled companies and asked the staff in charge of public safety to fill them in. When the subjects completed the questionnaire, we took it back before leaving. The survey began in December 2017 and finished in March 2018. All questionnaires were completed and taken back.

Table 1. Distribution of sample

\begin{tabular}{|c|c|c|c|}
\hline Area & County & Sample & Total \\
\hline Northern Taiwan & Taoyuan City & 121 & 127 \\
\hline & Kinmen County & 6 & \\
\hline \multirow{2}{*}{ Central Taiwan } & Taichung City & 68 & \multirow{2}{*}{78} \\
\cline { 2 - 3 } & Changhua County & 10 & \\
\hline Southern Taiwan & Kaohsiung City & 58 & 110 \\
\hline & Tainan City & 35 & \\
\hline & Taitung County & 17 & \\
\hline
\end{tabular}

\section{Data analysis and outcome}

After the questionnaire survey, the data were coded and analyzed. The analytical process is shown in Fig. 2. Details on each step of the process are given below.

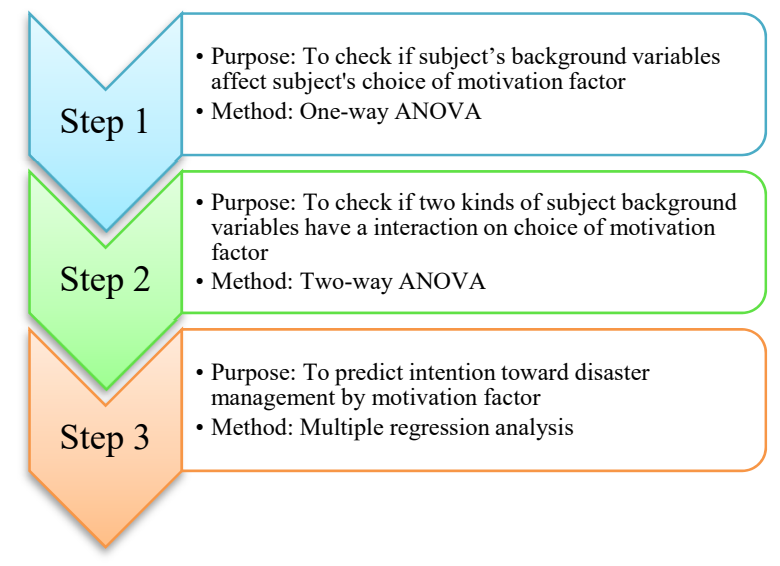

Fig. 2. Steps of data analysis

\subsection{Data analysis process}

\subsubsection{Step 1: The relationship between subjects' backgrounds and motivation factors}

In this step, the independent variable was subject background and the dependent variable was the choice of motivation factor. We conducted a one-way analysis of variance (ANOVA) to see whether the backgrounds of the subjects had an influence on their choice of motivation factor when considering implementing BCM for disaster management.

\subsubsection{Step 2: Interaction between subject background and motivation factor}

In order to understand if the subjects' choice of motivation factor (dependent variable), which was affected by one background variable (independent variable), was also influenced by the other background variable (independent variable) at the same time, we conducted a two-way ANOVA to explore the interaction between the two background variables.

\subsubsection{Step 3 : Prediction of intention toward disaster management based on background variables}

In this part, we regarded the motivation factors as independent variables and intention toward disaster management as the dependent variable. The statistical method used to analyze the data was multiple regression analysis, and our purpose was to elucidate the effectiveness of motivation factors when used to predict disaster management intention.

\subsection{Outcome of statistical analyses}

\subsubsection{Outcome of one-way ANOVA}

- Independent variable: Company capital; dependent variable: Organization (B-1)

The one-way ANOVA showed that different levels of "company capital" could affect subjects' choice of motivation factor B-1 (organization). The significant sub-items in "organization (B-1)" are shown in Table 2.

Table 2. Summary of ANOVA for significant items

\begin{tabular}{|c|c|c|}
\hline \multicolumn{3}{|c|}{ Independent variable: Company capital } \\
\hline $\begin{array}{c}\text { Dependent variable: Organization } \\
\text { (B-1) }\end{array}$ & F test & Sig. \\
\hline $\begin{array}{c}\text { B-1-1 Managers regard disaster management } \\
\text { as an important matter. }\end{array}$ & 3.762 & $0.003^{*}$ \\
\hline $\begin{array}{c}\text { B-1-2 Business customers ask about } \\
\text { implementing disaster management. }\end{array}$ & 2.789 & $0.018^{*}$ \\
\hline $\begin{array}{c}\text { B-1-3 Government strengthens the cooperation } \\
\text { between different organizations in } \\
\text { industry on disaster management. }\end{array}$ & 3.159 & $0.008^{*}$ \\
\hline
\end{tabular}

$* \alpha<0.05$

Since the outcome of the ANOVA was significant, we conducted a post hoc test (Tukey method). For B-1-1, we found that a company whose capital was over 100 billion NT\$ had a significantly larger average Likert score than a company worth 100 million NT\$.

Also, for B-1-2, the average Likert score for companies whose capital was over 100 billion NT\$ was significantly larger than that for companies whose capital was 1,000 million or 8,000 million NT\$.

For B-1-5, a company whose capital was over 100 billion NT\$ had a significantly larger average Likert score than a company whose capital was 1,000 million or 100 million NT\$.

- Independent variable: Hazardous materials; Dependent variable: Law (B-2)

The outcome of the one-way ANOVA showed that different levels of "hazardous material" affected subjects' choices regarding motivation factor B-2 (law). The details on the significant items for "law (B-2)" can be found in Table 3 . 
Table 3. Summary of one-way ANOVA for law (B-2)

\begin{tabular}{|c|l|l|}
\hline \multicolumn{2}{|l|}{ Independent variable: Hazardous materials } \\
\hline Dependent variable: Law (B-2) & F test & Sig. \\
\hline $\begin{array}{c}\text { B-2-1 The laws related to disaster } \\
\text { management and safety in } \\
\text { building construction for } \\
\text { industries should be strengthened. }\end{array}$ & 3.557 & $.007^{*}$ \\
\hline
\end{tabular}

$* \alpha<0.05$

Based on the outcome of the ANOVA, we continued on with a post hoc test. For B-2-1, companies with three locations housing hazardous materials had a significantly larger average Likert score than companies with four such locations.

Independent variable: Employee population; Dependent variable: Consultation (B-3)

The outcome of the one-way ANOVA showed that different levels of "employee population" could affect subjects' choices regarding motivation factor B-3 (consultation). The details of the significant items for "consultation (B-3)" are listed in Table 4.

Table 4. Summary of one-way ANOVA for consultation (B-3)

\section{Independent Variable: Employee population}

\begin{tabular}{|c|c|c|}
\hline $\begin{array}{c}\text { Dependent variable: Consultation } \\
\text { (B-3) }\end{array}$ & F test & Sig. \\
\hline $\begin{array}{c}\text { B-3-1 Government provides free } \\
\text { human resources to support } \\
\text { industries in dealing with } \\
\text { disaster management. }\end{array}$ & 2.056 & $0.048^{*}$ \\
\hline $\begin{array}{l}\text { B-3-4 Government provides } \\
\text { information, knowledge, and } \\
\text { materials on disaster mitigation } \\
\text { on Internet for industry to take } \\
\text { as reference. }\end{array}$ & 2.406 & $0.021^{*}$ \\
\hline
\end{tabular}

\section{$* \alpha<0.05$}

Since the outcome of the ANOVA was significant, we conducted a post hoc test. For B-3-1 and B-3-4, companies with an employee population of over 3,000 showed a significantly larger average Likert score than companies whose employee population was less than 6 people.

\subsubsection{Outcome of two-way ANOVA}

In order to determine if two background variables may have affected motivation factors simultaneously, we conducted a two-way ANOVA to check the significance of the interaction. As it was significant, we continued on to conduct a post hoc test (Tukey method).

The two-way ANOVA showed that two background variables, "employee population and "company capital," did affect the subjects' selection of motivation factors. The interaction approached significance, and a summary is presented in Table 5 .
Table 5. Summary of two-way ANOVA for consultation (B-3)

\begin{tabular}{|c|c|c|}
\hline \multicolumn{3}{|c|}{$\begin{array}{l}\text { Independent variables: Employee population and company } \\
\text { capital }\end{array}$} \\
\hline Dependent variable: Organization (B-1) & F test & Sig. \\
\hline $\begin{array}{l}\text { B-1-3 The selection of supply chain } \\
\text { manufacturers is based on their } \\
\text { capacity for disaster management. }\end{array}$ & 2.383 & $.001^{*}$ \\
\hline $\begin{array}{l}\text { B-1-4 In order to accept orders from } \\
\text { international customers, disaster } \\
\text { management for industries is } \\
\text { essential. }\end{array}$ & 1.955 & $.006^{*}$ \\
\hline
\end{tabular}

$* \alpha<0.05$

We conducted a post hoc test to learn the "simple main effect." When the employee population was over 100 , the main simple effect was shown in the subjects' choice related to the motivation factor "Organization." If a company had capital of 100 billion NT\$, its average Likert value was significantly larger than a company with 1 million NT\$ in capital (B-1-3) and 10 million NT\$ in capital (B-1-4).

\subsubsection{Outcome of multiple regression analysis}

Next, we took the average scores for "organization," "law," "consultation," "financial aid," and "education" as independent variables and the average score for intention toward disaster management as a dependent variable and conducted a multiple regression analysis. We found that three variables-"organization," "consultation," and "financial aid"-could effectively predict intentions toward disaster management. A summary of the results is shown in Table 6.

Table 6. Summary of multiple regression analysis

\begin{tabular}{|l|c|c|c|c|c|}
\hline & & \multicolumn{2}{|c|}{ Coefficient } & Std. C & \multirow{2}{*}{ Sig. } \\
\hline & $\mathbf{R}^{2}$ & B & $\begin{array}{c}\text { Std. } \\
\text { error }\end{array}$ & Beta & \\
\hline Constant $)$ & & .279 & .164 & & .090 \\
\hline Consultation & .503 & .356 & .051 & .354 & $.000^{*}$ \\
\hline Organization & .091 & .283 & .040 & .292 & $.000^{*}$ \\
\hline Financial aid & .037 & .288 & .052 & .286 & $.000^{*}$ \\
\hline Total & 0.62 & & \\
\hline
\end{tabular}

The multiple regression analysis returned an $\mathrm{R} 2$ of 0.62 . That means the three independent variables could explain $62 \%$ of the variance in the dependent variable. The most effective variable was "consultation," which could explain $50.3 \%$ of intention toward disaster management. The second was "organization," explaining $0.91 \%$, and the third was "financial aid," which only 
explained $3.7 \%$ of the variance. These three independent variables had variance inflation factor scores under 10 , so there was no collinearity problem. The regression of the equation used is shown in (1).

$\mathrm{Y}_{\text {Int. }} \wedge=0.279+0.356 \mathrm{X}_{\text {Con. }}+0.283 \mathrm{X}_{\text {Org. }}+0.288 \mathrm{X}_{\text {Fin. }}$

\section{Conclusion and suggestions}

\subsection{Research findings}

1. Company capital can affect motivation toward disaster management, especially as an organization factor, which would include a disaster response team for the company, a BCP, and cooperation with other industries after a disaster. The larger a company's capital, the more complex the BCM and related organization are. In other words, company capital is a quantitative index of disaster management. To maintain outside cooperation with other industries during a disaster and deal with disaster management during normal times, a company needs sufficient capital and an appropriate business scale. The findings meet the normal situation of the industry.

2. A company's employee population affects its selection of motivation factors. A company with a large employee population has a tendency to search for "consultation" on disaster management from the government. This finding shows that the human resources of disaster management are important for companies with a large employee population. Staff belonging to different sections of a company have different missions that relate to disaster mitigation. In fact, many staff do not know how to do in a viewpoint of $\mathrm{BCM}$; thus, consultation provided by the government is essential for industries.

3. The sample in this study was chosen from companies that handle hazardous materials. Another finding showed that the locations of such materials can prompt companies to choose "law" as a strategy to deal with disaster management. The reason is that Taiwanese laws related to hazardous materials are complicatedmore so than the laws related to industries' disaster management. Companies that handle hazardous materials will be fined if they do not meet the requirements set out in the related laws. Therefore, companies that store hazardous materials have a tendency to obey the law and atop the specific measures to deal with disaster management of BCM.

4. Two background variables, company capital and employee population, had an interaction with the motivation factor of organization. The relationship between company capital and employee population was positive in most cases. This is characteristic of large enterprises, and the emphasis of organizations on disaster management reflects international standards, because foreign customers or enterprises usually ask for a BCM and BCP, such as an ISO22301 series certification [7]. Besides, supply chain manufacturers are also asked to cooperate on disaster management.

\subsection{Suggestions}

Based on the findings, several suggestions on how to improve disaster management by industries that handle hazardous materials are listed below.

1. The government should provide consultation and education on disaster management for industries, so that they can gain relevant "know how." It should make complete laws, like the regulations on the storage of hazardous materials, for enterprises to obey. In this way, industries will not only realize what to do, but also what not to do; they will also know where to go for support.

2 . The government should counsel industries on building an internal disaster response organization and creating a demonstration for supply chain manufacturers to ensure cooperation when a disaster occurs. These measures should also be reflected in related laws and regulations. Besides, it should encourage agreements between different industries and related public sectors to ensure business continuity after a disaster.

3. At a reasonable scale, the government should provide specific support and loans to help enterprises prepare hardware related to disaster prevention and develop essential human resources. Also, evaluations of disaster management, such as a completion rate for BCP and details of BCM for natural disasters and accidents, should be conducted regularly. Furthermore, a fund for disaster management should be provided by different industries, so that if a company is damaged by a disaster, it can be rebuilt using the fund.

\section{Acknowledgment}

The author thanks the Ministry of Science and Technology in Taiwan for the financial support provided to this project 107-2119-M-015 -001.

\section{References}

1. National Fire Agency, Statistical report of official business, retrieved from http://statis.nfa.gov.tw/statisrpt/106H1/106H1.htm (2017)

2. S. Tsi, Thesis of National Taipei University of Technology, in Chinese (2005)

3. K. Li, C. Cao, IOSH report on labor safety and health, in Chinese, (2012)

4. S. J. Legg, K. B. Olsen, I. S. Laird, P. Hasle, Safety Science, 71, [189--176] (2015)

5. D. Champoux, J.P. Brun, Safety Science 41, 4 (2003)

6. L.V. Kvorning, P. Hasle, U. Christensen, Safety Science 71, 253-263 (2014)

7. ISO22301, Societal security — Business continuity management systems - Requirements, (2012)

8. S.T. Panwhar, R. Pitt, M.D. Anderson, Development of a GIS-based hazardous materials transportation management system, retrieved from https://trid.trb.org/view/681105 (2000) 
9. D. Osborne, T. Gaebler, Reinventing government: How the entrepreneurial spirit is transforming the public sector, from schoolhouse to statehouse, city hall to the Pentagon (Addison-Wesley Pub. Co., Massachusetts, 1993)

10. M. Dilley, R.S. Chen, U. Deichmann, A.L. LernerLam, M. Arnold, J. Agwe, P. Buys, O. Kjevstad, B. Lyon, G. Yetman, Natural disaster hotspots: $A$ global risk analysis, (2005) 